\title{
O RESGATE DE UM CORPO AUSENTE: TESTEMUNHO, MEMÓRIA E RESTOS EM ANTES DO PASSADO
}

\author{
THE RECOVERY OF AN ABSENT BODY: TESTIMONY, MEMORY \\ AND REMAINS IN ANTES DO PASSADO
}

Maria Rosa Duarte de Oliveiral

RESUMO: Trata-se do estudo do romance Antes do Passado - o silêncio que vem do Araguaia, de 2012, sob a perspectiva do resgate, via memória e testemunho, da história de Cilon Cunha Brum, um dentre os muitos militantes políticos da guerrilha do Araguaia, desaparecido na década de 70, e cujo corpo não foi encontrado até hoje. Este livro, que tem encontrado muita receptividade na crítica literária brasileira, traz para primeiro plano o sentido de uma ausência, seja pela busca fracassada do narrador-autor pela figura de um tio envolvido em heroicidade, seja pela narrativa entrecortada por lembranças, cartas, diários, fotos, restos de diálogos, imagens fugidias de um sujeito espectral, entre a visibilidade e a invisibilidade. Da mesma forma que o objeto da narração se dilui, o narrador também está cindido entre a subjetividade de marcas autobiográficas e o testemunho de outros, que trazem rastros de uma história cujo núcleo está vazio. A verdadeira testemunha não deixou nenhum vestígio de si, nem mesmo um corpo que pudesse atestar a sua morte. Entre a história e a ficção, a memória e o testemunho, a subjetivação e a dessubjetivação, esta narrativa se faz no intervalo do que ficou por dizer.

PALAVRAS-CHAVE: Literatura pós-ditatorial. Memória. Restos. Testemunho.

\begin{abstract}
This paper presents a study on the novel Antes do Passado - o silencio que vem do Araguaia, from 2012, under the perspective of recovering, through memory and testimony, of the story of Cilon Cunha Brum, one amongst many other political militants of the Araguaia's guerilla who disappeared in the 1970's and whose body has not been found yet. This book, that has been well received by Brazilian literary criticism, brings to attention a feeling of absence, that could be due to the unsuccessful search of the author-narrator for the figure of an uncle shrouded with heroism, or because the narrative is permeated by memories, letters, diaries, photos, dialog remains, evanescent images of a spectral being, between visibility and invisibility. In the same way that the object of the narrative dissolves, the narrator is also torn between the autobiographical subjectivity marks and other people's
\end{abstract}

\footnotetext{
${ }^{1}$ Prof ${ }^{a}$ Titular de Teoria Literária do Programa de Estudos Pós-Graduados em Literatura e Crítica Literária da Pontifícia Universidade Católica de São Paulo (PUCSP). São Paulo. Brasil. mrduarte@uol.com.br
} 
testimonies, which bring tracks of a story that has an empty nucleus. The true witness did not leave any traces of himself, not even a body to insure his death. Between history and fiction, memory and testimony, subjectivity and detachment, this narrative is built on what was left unsaid.

KEYWORDS: Post dictatorship literature. Memory. Remains.

Testimony. 
O testemunho vale essencialmente por aquilo que nele falta; contém, no seu centro, algo intestemunhável, que destitui a autoridade dos sobreviventes. As 'verdadeiras' testemunhas, as 'testemunhas integrais' são as que não testemunharam, nem teriam podido fazêlo.

Giorgio Agamben

$\mathrm{O}$ vínculo entre literatura e testemunho, embora tenha sido mais estreito e visível no século XX, palco de tantas guerras e genocídios, é bem mais antigo. Podemos perceber no relato de viajantes, por exemplo, esse traço de registro do vivido, sempre mediado, porém, pela perspectiva daquele que observa, seleciona e interpreta à luz de seu repertório cultural. Os cronistas também, a seu modo, não deixam de se manifestar em seus relatos o testemunho de seu tempo transformado, como diria Machado de Assis, pelo olhar de míope que "vê o oculto e o escondido" em cada ato do cotidiano.

No entanto, é no século XX que o aumento significativo dos relatos de prisioneiros e de sobreviventes de catástrofes de guerras e genocídios, tendo em Auschwitz seu ponto extremo, que se pode falar de uma "literatura de testemunho", termo alvo de muita polêmica por seu caráter classificatório de "gênero", com o objetivo de revelar ao mundo o que ficou calado pela voz de tantos que morreram no esquecimento.

$\mathrm{Na}$ América Latina e no Brasil, especificamente, foram os vinte anos de ditadura militar (1964-1984) que legaram grande número de autobiografias, diários e romances, nos quais se revelam graus de "teor testemunhal" ${ }^{2}$ variados. Isso significa uma convivência não

\footnotetext{
${ }^{2}$ Para Márcio Seligmann-Silva - um dos mais renomados pesquisadores sobre o tema, em seu livro O local da diferença. Ensaios sobre memória, arte, literatura e tradução (2005) -, o termo "teor testemunhal" é melhor
} 
pacífica e assimétrica entre o referencial e suas marcas históricas e a rememoração, com sua inevitável alteração do vivido pela subjetividade daquele que narra. Assim também, entre o registro, puro e simples, e a escritura ${ }^{3}$, há o intervalo da escolha e responsabilidade pela forma, isto é, um ato escritural consciente de que a escrita é o "ter-lugar"4 de onde emana o acontecimento em sua presença viva e luminosa. Isso difere o escritor daquele que apenas registra e faz da língua mero instrumento, alienado de sua força vital e criadora de mundos possíveis.

As narrativas de testemunho podem assumir ou o caminho da mimese do ocorrido, numa atitude reprodutora, ou deslocar-se para, numa zona intervalar, ofertar uma resposta crítica entre o estético e o político, incluindo na enunciação a voz e a perspectiva do outro, bem como, em chave metadiscursiva, dar lugar à voz daquele que escreve, revelando o seu débito com a incapacidade de dizer, vivida no seu limite mais extremo. Trata-se, então, de um deslocamento para uma zona cujo foco está nos que não sobreviveram, nos que foram calados pela história, mas não sob a perspectiva da heroicidade ou da vitimização, libertando o discurso de dicotomias paralisantes e empobrecedoras. Permanecer no limiar é o maior desafio dos relatos de testemunho.

Entre a ética e a responsabilidade com o ocorrido e aquela exigida pela escritura, cujo habitat é o território literário, é que está a cisão na qual se debate a literatura de testemunho. Como é possível denunciar a catástrofe, compromissado com a verdade de falar pelos que não sobreviveram e, ao mesmo tempo, responder à necessidade de torna-la presença na linguagem, não como meio de representação, mas como presença viva, autônoma e intransitiva? Seligmann-Silva traduz com limpidez esse impasse:

Esta literatura implica, portanto, uma nova ética de representação [...] Há espaço apenas para as imagens secas, para os hieróglifos da memória fragmentada, para a literalidade da escrita: para uma nova relação com a esfera da morte e com o campo dos signos subordinado a essa esfera. Aqui, portanto, sem desaparecer totalmente, deixam de comandar a produção artística os jogos das vanguardas com a ironia e com a alegoria (esses jogos são agora como que travados por essa nova estética e ética do sublime caracterizada por uma presença daquelas imagens mudas que exigem uma nova performance da linguagem). (2005, p.111; grifos nossos).

Essa tensão responsável por uma nova ética de representação redimensiona a escrita literária e seu caráter testemunhal não pelo viés da criação de personagens ficcionais, mas pelo processo de enunciação no qual a língua é o "ter-lugar" onde o sentido e as ideias se mostram como figuras "secas, hieróglifos da memória fragmentada", mobilizadoras do pensamento e da ação. Ao invés de personagens, as "dramatis personae" estão na língua. A dramática da língua ao invés da gramática. Dramática que se atualiza na convulsão entre o que se diz e o que ficou por dizer. Entre ato e "potência de não", daquilo que poderia ter sido enunciado e não foi. A língua como um "aqui" que se mostra como lugar de uma voz muda que dá testemunho da impossibilidade de dizer.

do que o de "literatura de testemunho", tendo em vista que o testemunho pode aparecer nos mais variados gêneros como: a crônica, o romance, as memórias, os diários, etc. (2005, p.91 e 111).

${ }^{3}$ O termo "escritura" é de Roland Barthes em seu livro O grau zero da escritura, cuja 1a. edição é de 1953, e significa o ato escritural em sua intransitividade e responsabilidade pela forma.

${ }^{4} \mathrm{O}$ termo é de Giorgio Agamben e com ele quer mostrar a língua como o espaço no qual o homem habita, muito embora não tenha consciência de que é na singularidade desse "ter-lugar" que o seu pensamento e o seu estar no mundo se faz. Cabe à literatura, então, assumir uma espécie de "língua estrangeira" que se basta na contemplação de seu poder de dizer/não dizer, resistindo à comunicação e à informação porque se sabe incapaz de nomear definitivamente os seres e as coisas. Contemplar a língua em seu "ser de infância", é dar testemunho de sua pura potencia de não dizer/dizer, que constitui a ética e a responsabilidade do escritor. 
[...] podemos dizer que dar testemunho significa pôr-se na própria língua na posição dos que a perderam; situar-se em uma língua viva como se fosse morta, ou em uma língua morta como se fosse viva [...] Não causa surpresa que tal gesto testemunhal seja também o do poeta, do auctor por excelência. [...] significa, sim, que a palavra poética é aquela que se situa, de cada vez, na posição de resto, e pode, dessa maneira, dar testemunho. Os poetas - as testemunhas - fundam a língua como o que resta, o que sobrevive em ato à possibilidade - ou à impossibilidade - de falar. (AGAMBEN, 2008, p.160)

Pode causar espanto este vínculo que Agamben estabelece entre o testemunho e o poeta, o auctor por excelência como denomina, e, neste ponto, é legítimo que interroguemos: a língua, e a língua poética em especial, pode nos oferecer que tipo de testemunho? Sobrevive a qual naufrágio, a qual catástrofe?

Efetivamente, não se trata de estetizar o ato dilacerante de testemunhos de sobreviventes de catástrofes, cuja necessidade de escrever surgiu como última resistência do humano a um limite ao qual foi submetido. Aliás, um paradoxo, conforme Raul Antelo (2004, p.139) observa, que se instaura entre impossibilidade e necessidade, pois "para que um sujeito seja destituído, é imprescindível contar com uma impossibilidade (a expulsão do possível), articulada a um imperativo (que negue aquilo que pode não ser)".

No âmbito destas reflexões, a experiência na língua do in - testemunhável aponta, também, para o fracasso do ato criador e da própria representação, sempre em falta com aquilo que não está na obra, mas que ambos, corajosamente, buscam apreender, mesmo sabendo que partem de uma conflito insolúvel, isto é, o desejo de avançar em direção a um sentido e, ao mesmo tempo, a impossibilidade que os faz retroceder para aquilo que ficou emudecido, como potência de uma língua no campo infinito de sua possiblidade de não dizerdizer. Um "lugar deslocante" (ANTELO, 2004, p.143) e de passagem de um puro gesto em direção ao inapreensível. Sem mérito, sem sublimação, sem epifania que não seja a única possível: a do in-apreensível silêncio do "trono vazio", que está no centro, como Agamben nos mostra com agudeza, de qualquer dispositivo de poder e de gloria, inclusive o da língua.

Trata-se, então, seguindo ainda o percurso que Agamben elaborou em $O$ que resta de Auschwitz, de aprofundar esse laço que une pela língua, no limite entre o articulável e o in articulável, o testemunho e a poesia, por caminhos diferentes: a primeira, pelo limite do humano e a segunda, pelo da própria língua em desaparecimento.

Nesse sentido, a língua viva dá testemunho do balbucio de uma língua "morta", em estado de emudecimento de uma não-língua, que sobrevive no intervalo entre indizíveldizível, mas que, paradoxalmente, é o lugar originário de sua in-fância, fonte regeneradora de vida em potência máxima - a liberdade de poder ser/expressar associada ao risco de poder não ser/ expressar (a contingência). Esse deslocamento, que permite ao autor "colocar-se na língua na mesma posição daqueles que, como o "muçulmano", a perderam, deflagra o gesto profanador e vazio que está no centro da máquina do discurso e que responde por uma ética de responsabilidade entre a necessidade e a impossibilidade:

Talvez cada palavra, cada escritura nasce, nesse sentido, como testemunho. E, por isso mesmo, aquilo de que dá testemunho não pode ser já língua, já escritura: pode

\footnotetext{
${ }^{5} \mathrm{Na}$ imagem do "trono vazio", recorrente na história do poder político e religioso, Agamben identifica aquilo que esse símbolo deseja ocultar: a sua potência de não-governabilidade e de vazio inoperante (ver em "Arte, inoperatividade, política", conferência proferida por Agamben na Fundação Serralves, no Porto, em 2007.)

${ }^{6} \mathrm{O}$ termo "muçulmano", usado no jargão do campo de Auschwitz, refere-se àquele que chegou ao limite do humano, um morto-vivo, sem identidade, sem pátria e sem língua que reconheça como sua. É a verdadeira e única testemunha da catástrofe que, no entanto, não pode testemunhar por não ter sobrevivido a ela. Dele, resta, apenas, o intestemunhável inscrito, paradoxalmente, nos relatos de testemunho.
} 
ser somente um não-testemunhado. Isso é o som que provém da lacuna, a nãolíngua que se fala sozinho, de que a língua responde, em que nasce a língua. $E$ é sobre a natureza deste não- testemunhado, sobre a não-língua que é preciso interrogar-se. (AGAMBEN, 2008, p.47; grifos nossos)

Esta é uma outra perspectiva ética que se abre para a linguagem poética, em prosa ou em verso, como testemunho do lugar vazio, no campo deslocante que opera na instituição, seja ela literária ou linguística.

Antes do Passado, o silêncio que vem do Araguaia, romance publicado em 2012, vem ao encontro do que dissemos trazendo um questionamento: em que medida poderia se inscrever nele algum tipo de "teor testemunhal", bastante comum na produção literária brasileira do período pós-ditatorial?

Não se trata, propriamente, de uma escrita testemunhal, mas sim da reconstrução de um rosto, de um nome do qual só restaram pedaços perdidos em fotos, cartas, documentos esparsos e, especialmente, na memória daqueles que podem atestar sua existência. Esta é uma narrativa cuja autora, Liniane Haag Brum, tem por meta a busca por Cilon Cunha Brum, seu tio e padrinho, um dentre os muitos militantes políticos brasileiros da guerrilha do Araguaia, desaparecido na década de 70. Um "desaparecido político", portanto, que ficou entre a existência e a não- existência, já que nem mesmo a morte pode ser confirmada pela ausência da maior prova: o corpo.

Apesar deste laço biográfico, a narrativa alcança densidade própria por meio de uma escrita na qual a "impossibilidade de dizer" se instaura por meio das tensões não resolvidas entre versões que se negam, entre a diversidade de tons - das notícias de jornais de época, de documentos oficiais, de fotos e cartas reais e imaginárias, de relatos truncados de testemunhas - bem como de um narrador cujo relato se vê continuamente à beira do abismo do inenarrável.

Eis aí uma espécie de "dramática" da língua, como dissemos, inscrita na forma poética fragmentária, que trunca a continuidade da linha e de uma história biográfica linear, investindo na justaposição de matérias e tons discursivos diversos, cujos intervalos atestam as lacunas e os vazios daquilo que ficou por dizer. Cabe ao leitor a responsabilidade de, nesta montagem entre ficção e história, criar as conexões, gerando interpretações falíveis e, também, sujeitas à contingencia do poder /não poder ser.

Este livro, que tem encontrado muita receptividade na crítica literária brasileira, traz para primeiro plano o sentido de uma ausência, seja pela busca fracassada do narrador-autor pela figura de um tio envolvido em heroicidade, seja pela narrativa entrecortada por lembranças e indícios testemunhais por meio de cartas, diários, fotos, documentos e entrevistas que criam imagens fugidias de um sujeito espectral, entre a visibilidade e a invisibilidade.

\footnotetext{
Fogo-fátuo

Tio Cilon me acompanhou sempre. Era alto, magro, cabelo preto e liso, repartido ao lado. Tão bonito. Meu padrinho era lindo.

Pena que quando eu nasci ele desapareceu (BRUM, 2012, p.19)
}

Desde o início, o narrador posiciona-se dentro e fora do relato, simultaneamente: de um lado, o objeto do narrar é a "imagem fantasmática" de um tio de cuja presença não partilhou; de outro, no "fogo-fátuo" do título, posiciona-se sobre a emotividade do discurso e lança uma interpretação metafórica, alicerçada sobre o paralelismo entre o fenômeno real do fogo-fátuo - comum nos cemitérios nos quais estranhas chamas azuladas aparecem e 
desaparecem sem deixar vestígios como efeito da decomposição dos corpos - e o fantasma de uma ausência cuja presença é o mote que percorre toda a narração.

Esta presença da ausência se faz notar num dos fragmentos mais impactantes do relato: aquele no qual se faz ver a lápide pelo que não diz: "Esta sepultura aguarda o corpo de Cilon Cunha Brum":

\section{AGUARDAR}

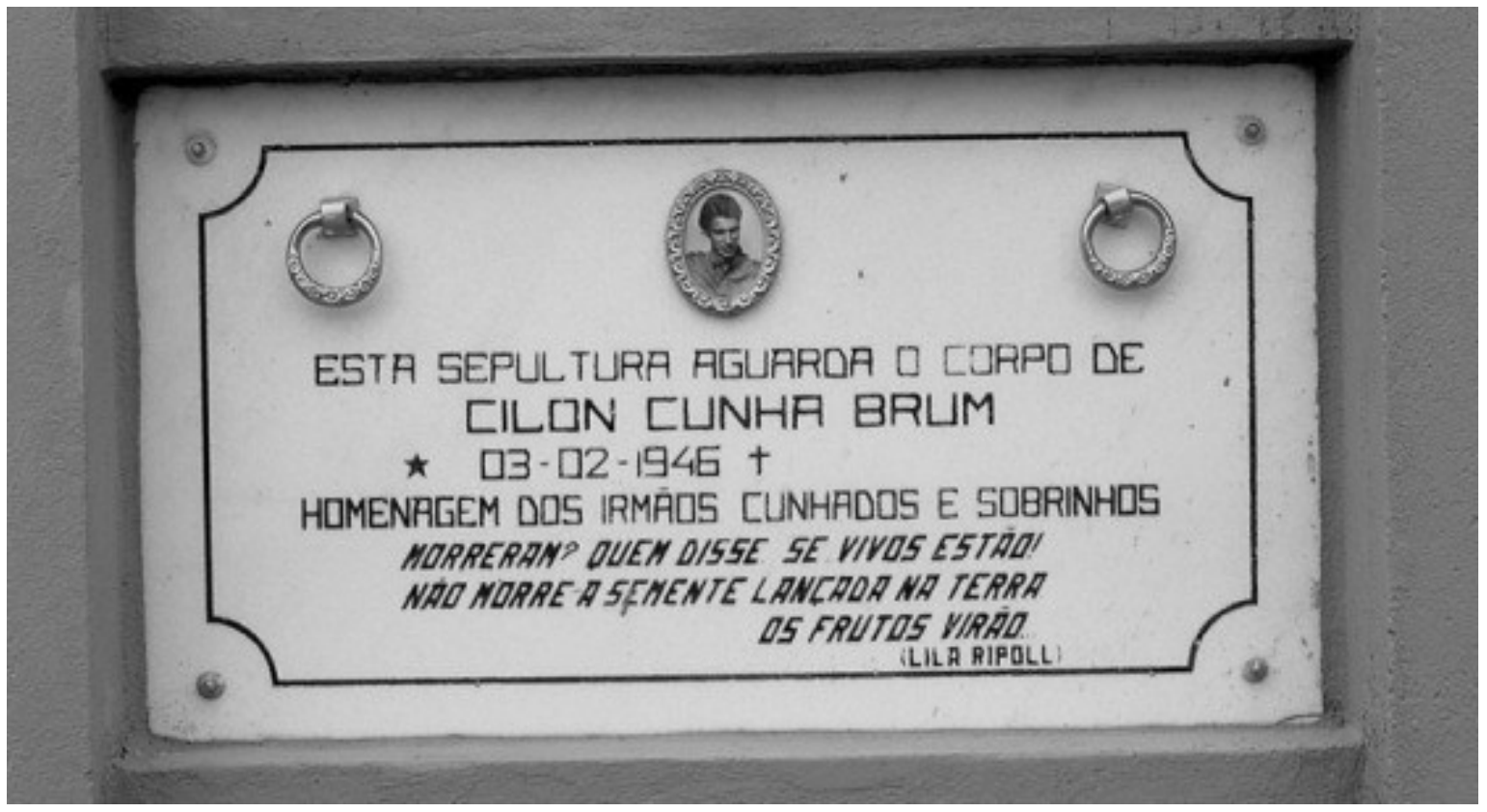

O tempo para e se dilata nesse "aguardar". Nesta anti-lápide, paradoxalmente, se inscreve a voz muda da única testemunha que conta, a do próprio Cilon, cujo corpo está sendo ainda esperado. Diz justamente pelo que deixou de dizer e é de uma força expressiva inigualável. De sorte que é de se perguntar realmente: "Morreram? Quem disse se vivos estão!"

E é assim que a narrativa vai sendo tecida por uma linha irregular na qual "impressões fantasmáticas" aparecem e desaparecem, feito "fogo fátuo", por meio de fragmentos de cartas, jornais de época, fotos, depoimentos de testemunhas, cujos elos estão ausentes e devem ser reconstruídos pelo leitor, cúmplice de uma busca por um corpo que é, apenas, miragem.

Indícios testemunhais deste corpo ausente devem ser reconstruídos pelo leitor por entre os espaços desta narrativa em "fogo fátuo": 


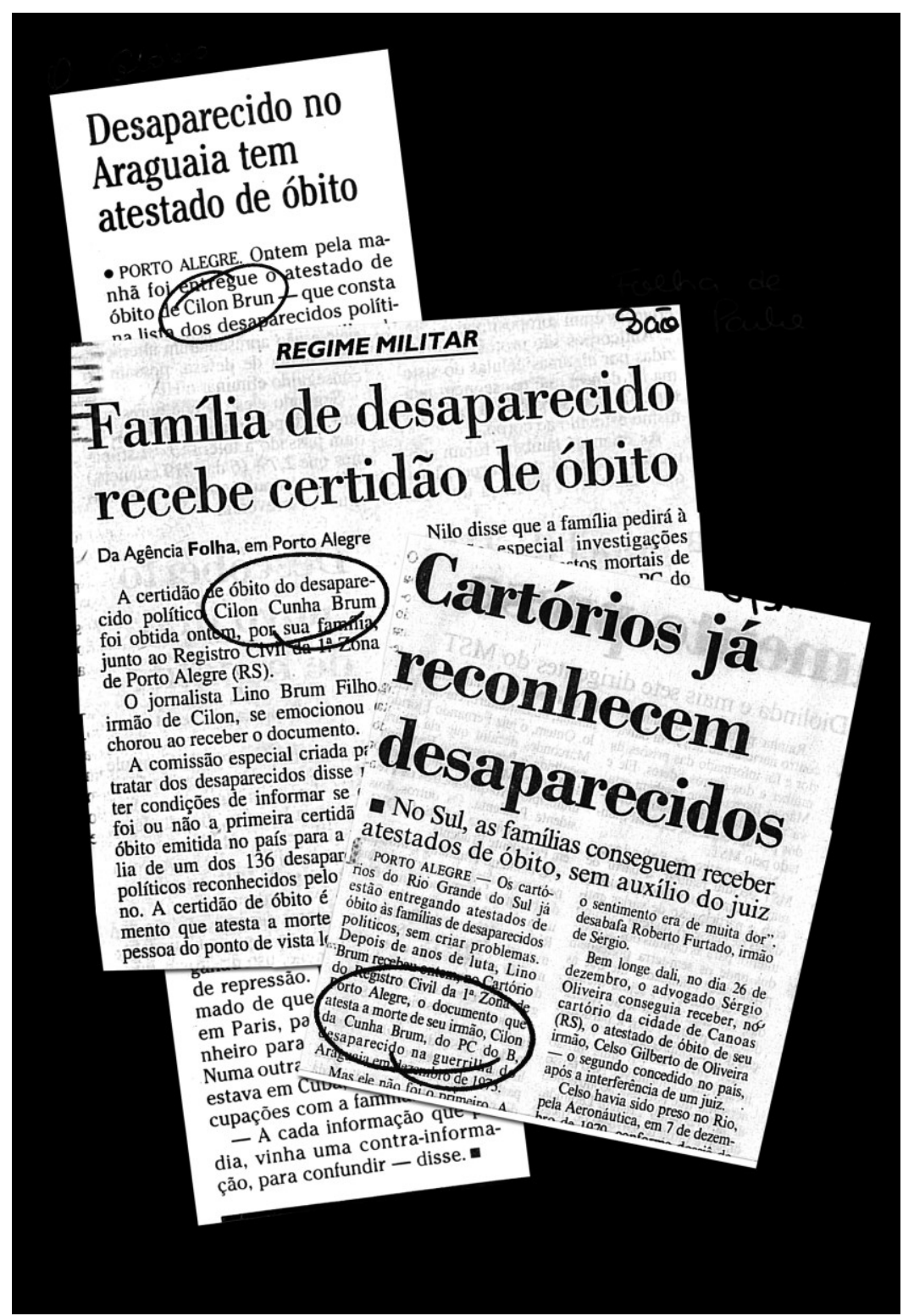

Ao lado desses recortes de jornais, há ainda cartas, como a do exemplo abaixo, na qual o "rogar" fica como um pedido sem eco:

Rogar

São Sepé - RS, julho de 1981

Venho por via desta, como mãe aflita, solicitar informações sobre o destino de meu filho CILON CUNHA BRUM [...] Neste mês de julho completa 10 anos que não obtenho informações do mesmo. Sei que nos anos 1970/71 esteve envolvido em atividades subversivas de esquerda, em São Paulo, usando o codinome SIMÃO. Naquele mês recebi, dele, sua última e lacônica carta que 'vou ficar uns tempos fora'. [...] Rogo, pois, em última instancia, que me forneça informações precisas que possa matar a aflição que vivo há 10 anos, o que para uma mãe representa uma eternidade. [...] Os órgãos de segurança do Rio Grande do Sul limitam-se a informar que 'nada consta'. (BRUM, 2012, p.51)

Mas o que chamaríamos de "teor testemunhal", no entanto, pode ser vislumbrado em momentos nos quais o narrador se coloca na tarefa detetivesca de recolher pistas, restos de lembranças fugidias daqueles que conviveram com o tio Cilon e puderam dar testemunho de pedaços de sua vida e morte. O episódio do relato de uma testemunha - Dona Nazaré -, é bastante significativo: 
[...] "A Maria da Paz me falou da senhora", revelei, por fim.

Nazaré olhou para um dos homens, para outro - e disse: "não sei de nada não, nunca vi ninguém". Depois, num intervalo de tempo tão curto, numa atitude cujo significado me escapou, virou para todos nós e afirmou, de uma só vez:' "Eu conheci o Simão, foi o único deles que vi. O único. Eu tava em casa sozinha e o meu caçula, ele tava cortando pau, e eu dentro de casa. De repente percebi que parou o barulho do machado na madeira, já ia saindo para ver quem tinha chegado, veio o meu menino com uma arma na mão: 'Mãe, é o povo da mata, o homem veio se entregar, trouxe essa arma'. [...] Diz que fugiu, que os companheiros dele ficaram para trás.' É só isso que eu sei”. [...] Expliquei a ela sobre as entrevistas, o livro [..] ela repetia a história, mais uma, duas vezes, inteira e aos pedaços, cada vez mais acrescentando detalhes - explicando ao final que não tivera alternativa: "Precisava entregar o povo da mata, senão os companheiros dele vinham e aí era pior". (BRUM, 2012, p.236)

O relato pontuado de idas e vindas, povoado por contradições e esquecimentos, deixa o narrador e seu leitor perplexos, na incerteza de um espaço ambivalente feito de impressões fugidias sobre as quais não se pode ter certeza alguma. $O$ acontecimento não pode ser representado porque suas marcas estão em desaparecimento. Eis aí toda a problemática deste relato testemunhal escorregadio.

Não resta ao narrador senão a alternativa de investir numa outra versão, tão falível quanto a da "testemunha ocular", mas que assume a sua responsabilidade com a escritura e seu teor ficcional, isto é, aquele que investe na consciência de que narrar é um ato enunciativo e fabulador por excelência:

Eu não estava inteira ali desde que Nazaré terminara seu relato. Meu pensamento dava voltas, indo e vindo sempre na mesma cena: ele vinha pela beirada de um rio. Um riacho adjacente: o Saranzal. Acabara de deixar os companheiros para trás seguia o curso d'água, meio trôpego, combalido pelo cansaço. Vinha caminhando pela beirada das águas turvas, protegido pela tessitura do arvoredo que formava um túnel verde de uma margem à outra. [...]Rendendo-se de própria vontade, dentro das leis de guerra, teria chance de negociar (ou salvar) a própria vida. Simão Comprido, tio Cilon - seguiu esgueirando-se até o som do machado ficar tão nítido quanto o de sua respiração [...] dali espreitou o jovem a golpear o altíssimo tronco. Ficou nessa posição até que se criou o momento oportuno - de gritar de onde estava com a carabina na mão, pegando no cano e estendendo o cabo para o moço: "Sou Simão, vim me entregar, o revólver tá carregado de bala". (BRUM, 2012, p.237238)

Entre o que diz e o que não diz, cria-se um intervalo que oferece ao narrador a oportunidade de dizer de outro modo, inventar uma outra cena na qual possa partilhar da presença de um Cilon vivo, apenas, no espaço imaginário da narração. Em ambas, porém, é no que não foi dito que jaz a voz muda e inapreensível da testemunha integral dos acontecimentos - a do próprio Cilon, entre não-personagem/personagem, - cuja fala permanece muda.

A maioria das coisas acontece num espaço onde jamais uma palavra penetrou.

Rainer Maria Rilke

Esta epígrafe, que surge ao final de Antes do Passado, tem o dom de nos inspirar neste momento conclusivo. Com efeito, Rilke aponta, agudamente, para a consciência de que lá, na raiz nascente de uma língua, impera a mudez do signo que quer significar mas suspende 
esse movimento em direção ao sentido para usufruir desse espaço intervalar da potência de não dizer/dizer, experimentando a contingencia absoluta de poder - não poder ser. A ética de uma escritura, seja ou não testemunhal, passa por essa "responsabilidade pela forma", isto é, a consciência do fracasso de toda representação na captura da "verdade" de um acontecimento, da reconstrução de um rosto, de um nome, de uma biografia, como acontece em Antes do Passado.

Ao narrador, por isso, só restam pedaços, frágeis pontos dispersos aqui e ali numa narrativa truncada e incapaz de reconstruir a linha de uma história perdida e inconclusa. Onde procurar a verdade do desaparecimento de Cilon Cunha Brum? Esse tio-padrinho espectral que, como o "pai" de "A terceira margem do rio", de Guimarães Rosa, permanece como um vulto ali, na outra margem, nessa fissura onde o que impera é a potência de uma impossibilidade de dizer, a presença de uma palavra muda que resiste na raiz do próprio relato.

A verdadeira testemunha, a única que poderia trazer a verdade à luz, não deixou nenhum vestígio de si, nem mesmo um corpo que pudesse atestar a sua morte. E aqueles que falam em seu nome, só podem oferecer uma palavra muda, como diz Giorgio Agamben na epígrafe deste ensaio. Entre a história e a ficção, a memória e o testemunho, esta narrativa se faz no intervalo do que ficou por dizer

\section{REFERÊNCIAS}

AGAMBEN, Giogio. Arte, inoperatividade, política. In: Política: Agamben, Marramao, Rancière, Sloterdijk-Crítica do contemporâneo. Conferências internacionais Serralves. Tradução: Simoneta Neto. Lisboa: Fundação Serralves, 2008.

. O que resta de Auschwitz. O arquivo e a testemunha. Homo Sacer III. Tradução Selvino J. Assmann. São Paulo: Boitempo, 2008.

ANTELO, Raul. Paradoxos do testemunho. In: Potências da imagem. Chapecó: Argos, 2004. p.138-142.

BARTHES, Roland. O grau zero da escrita. Tradução Mário Laranjeira. São Paulo: Martins Fontes, 2004.

BRUM, Liniane Haag. Antes do Passado. O silêncio que vem do Araguaia. Porto Alegre: Arquipélago, 2012.

SELIGMANN-SILVA, Márcio. O local da diferença. Ensaios sobre memória, arte, literatura e tradução. São Paulo: Editora 34, 2005.

Recebido em: 04 de fevereiro de 2015.

Aceito em: 01 de junho de 2015. 